\title{
The Research on Flatness Control Simulation for Cold Tandem Rolling Mills
}

\author{
X.M. Zhou, X.X. Yue \\ School of Mechanical Engineering \\ University of Science and Technology Beijing \\ Beijing, China
}

\begin{abstract}
The cold tandem rolling of metal strip presents a significant control challenge because of nonlinearities and process complexities. Flatness control system is a hot topic on cold tandem rolling process. The process parameters and state variables cannot be measured due to the rolling process complexities. So it is important how to indicate the rolling process parameters change during the whole rolling process. The rolling model is established by considering the elastic deformation of the roll and plastic deformation of the strip as a whole. The verified results represent that the flatness control integration simulation system can reflect the rolling process parameters and flatness effectively.
\end{abstract}

Keywords-flatness control; simulation; cold tandem rolling Mill

\section{INTRODUCTION}

The flatness and the gauge accuracy are the most important factors in evaluating the quality of a strip [1]. Customers' needs for product quality are higher and higher. To meet the demand for the high quality strip, steel makers and researchers pay attention to the flatness control significantly. But the cold tandem rolling of metal strip presents a significant control challenge because of nonlinearities and process complexities [2][3]. Nowadays, there are a lot of problems to resolve for the high precision flatness control because of the rising rolling speed and the more improving flatness control actuators [4][5][6]. The traditional model establishment is hard to deal with the more and more complex control process [7][8]. And the measurement of the process parameters online is also difficult to achieve. With the rapid improving of the computer technology, the simulation system based on the experimental data can be used to analyse and debug the control tragedy and model for rolling process [9][10][11]. It is very important to the actual process and research.

In this paper, the rolling model is established by considering the elastic deformation of the roll and plastic deformation of the strip as a whole. The verified results represent that the flatness control integration simulation system can reflect the rolling process parameters and flatness effectively.

\section{THE ESTABLISHMENT OF THE SIMULATION SYSTEM}

The simulation system is established in which elastic deformation of the roll and plastic deformationofthestripare considered as a whole. The simulation is for five stands 6-high tandem cold rolling mill. The diameter of the backup roll is $1276 \mathrm{~mm}$. The diameter of the intermediate roll is $467 \mathrm{~mm}$. The diameter of the work roll is $426 \mathrm{~mm}$. The roll finite element deformation model is shown as Figure 1.

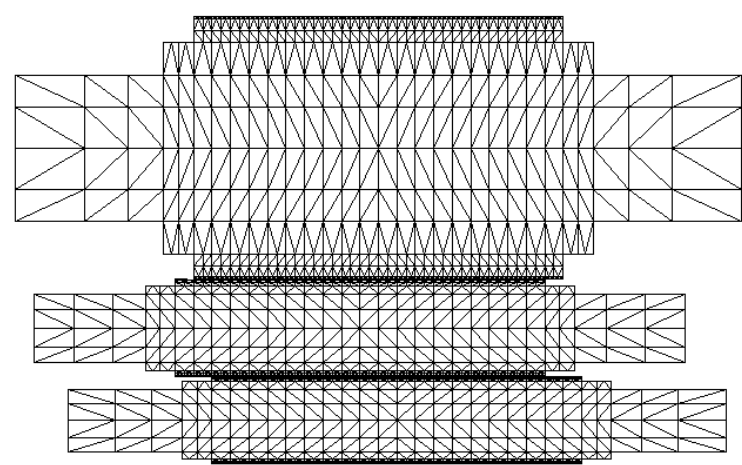

FIGURE I. ROLL DEFORMATION MODEL

For flatness control process, the most important role of the strip plastic deformation calculation is to decide the rolling force distribution and tension distribution. It is hard to achieve due to the physical and geometry nonlinearity and the complexity of the boundary condition for the rolling process.

The model research of the cold rolling process is based on the traditional theory of Kalman equation and Orowan equation under the condition of the two-dimension plane strain assumption. The strip deformation can be considered be produced on the thickness and the rolling direction. The deformation in the strip width direction can be ignored. But this kind of model is clearly not appropriate for studying the strip edge drop characteristics. Because the edge drop generation depends not only on the work roll deflection and flatten, but also depends on the strip three-dimensional plastic deformation caused by the lateral flow of metal near the strip edge. If the strip deformation in the width direction is ignored because of using the two-dimensional model to solve this problem, the real situation of the strip flatness cannot be reflected actually. So the three-dimensional plastic deformation model must be established to consider the strip transverse flow during the rolling process.

The three dimensional differential method is used to calculate the strip plastic deformation in this paper. The vertical and horizontal balance differential equations of the deformation zone are transferred to the differential form. Then these equations are united with the plasticity condition, plastic flow equation, constant volume conditions and boundary conditions, the three-dimensional stress distribution of the deformation 
zone and the edge curve of the strip can be calculated using the numerical and iterative method.

The entry and exit longitudinal stress $\sigma x$ are known parameters of the differential calculation. The assumed transverse deformation values of the edge units are the initial values of iterative computation. The differential calculation of the whole deformation zone is from the first unit of the edge.

The integration model of the roll and strip combines the strip plastic deformation model and the roll elastic deformation model. The exit strip profile is the output of the roll elastic deformation model. And it is the input of the strip plastic deformation model. The calculated rolling force distribution from the strip plastic deformation model compared with the assumed rolling force distribution. If the deviation meets the deviation requirement, the calculated results are the final output Otherwise the rolling force distribution is updated to repeat the above iterated steps until the condition is satisfied. The outputs include the rolling force distribution, the exit strip profile and the front tension distribution. The calculation flow chart of the integration model is shown as Figure 2.

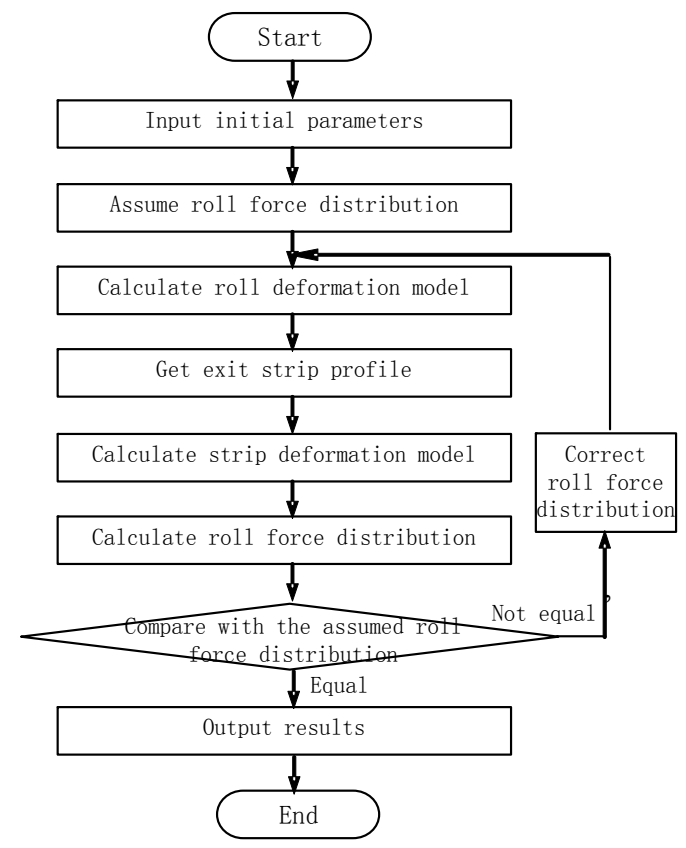

\section{FIGURE II. THE CALCULATION BLOCK DIAGRAM OF THE INTEGRATION MODEL}

The whole model is the integration of the strip plastic deformation model and the roll elastic deformation model. The roll elastic deformation model is calculated by the variable thickness finite element method which has the high calculation speed and precision. The strip plastic deformation model is calculated by the three-dimensional differential method which can reflect the actual strip deformation precisely considering the transverse flow in rolling zone.
The model can analyse the flatness influence factors from the roll and strip such as roll shape including the initial roll shape, thermal roll shape and wear roll shape, roll bending, roll shift, strip material, entry strip profile and tension etc. So this simulation system is the comprehensive means for the shape characteristics research. And it can simulate the strip edge deformation precisely, so it is important method to analyse the edge drop for flatness control.

\section{THE VERIFICATION OF THE MODEL BY EXPERIMENTAL DATA}

To verify the model reliability and precise, the sampling experiment was carried out in the cold tandem rolling mill. To retain the whole deformation zone and ensure the maximum production capacity, the sampling experiment is carried out before the backup roll changing. The whole deformation zones of the five stands can be obtained by lifting rolls during the normal rolling process. And the corresponding process parameters and rolling parameters are recorded at the same time. The integration model is verified by these valuable experimental data.

The spiral micrometre (measurement precision of 0.001 $\mathrm{mm}$ ) is used to measure the entry and exit transverse thickness distribution of the strip near the deformation zone. The sampling measurement positions are shown as Figure 3.

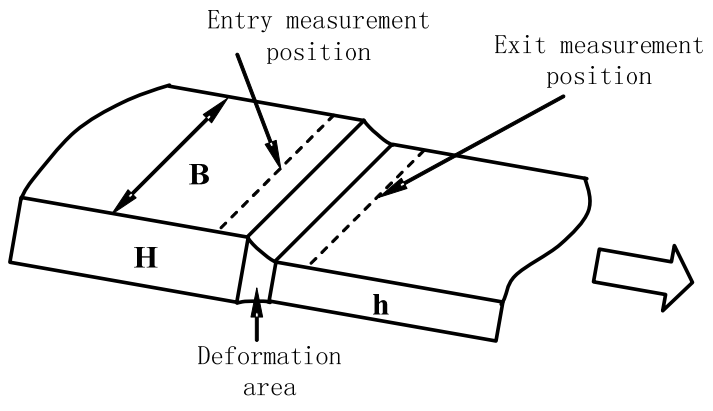

FIGURE III. THE SAMPLING MEASUREMENT POSITIONS

The strip thickness measurement is from the work side (WS side) to the drive side (DS side) across the strip width. In order to study the edge drop of the strip, the measurement is fine in the strip edge. These measurement data describe the entry and exit strip transverse thicknessdistribution of each stand.

The correspondingrolling parameters, process parameters and the measured entry thickness distribution are the input of the integration system to calculate. To compare the calculated exit thickness distribution of each stand with themeasuredvalues of each stand, the accuracy of the model can be analysed.

The comparison of the stand 1exit strip measured values and calculated values are shown as Figure 4. The comparison of the stand 5exit strip measured values and calculated values are shown as Figure 5. It can be seen from Fig. 9 and Fig. 10 thatthe integration model can achieve the satisfied precision for the flatness control simulation.By the comparison of the measured values and calculated values, the 
calculated strip transverse thickness distribution are very close to the measured values including the edge zones.



FIGURE IV. THE COMPARISON OF THE STAND 1 EXIT STRIP BETWEEN SIMULATION AND MEASUREMENT

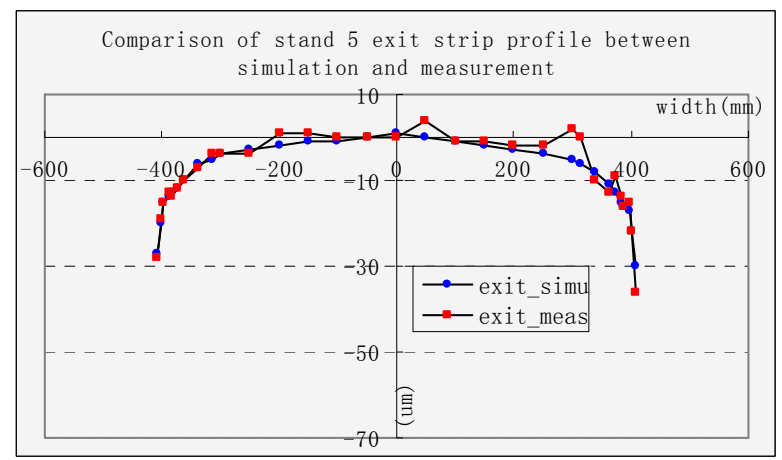

FIGURE V. THE COMPARISON OF THE STAND 5 EXIT STRIP BETWEEN SIMULATION AND MEASUREMENT

\section{CONCLUSION}

In this paper the rolling model is established by considering the elastic deformation of the roll and plastic deformation of the strip as a whole. The simulation system is verified by experiment data from the five stands 6-high tandem cold rolling mill. The verified results represent that the flatness control simulation system can reflect the rolling process parameters and flatness effectively. This simulation system can be used to analyse the flatness control process including the edge drop control.

\section{ACKNOWLEDGEMENTS}

We would like to acknowledge the financial support by National Natural Science Foundation of China through Grant No.51204017.

\section{REFERENCES}

[1] Bilkhu T.S. Dynamic Control of Tension, Thickness and Flatness for a Tandem ColdMill. AISE Steel Technology, 2001,78(10),pp49-pp54.

[2] A. BEMPORAD, D. BERNARDINI, F. ALESSANDRO,et al. Optimization-based Automatic Flatness Control in Cold TandemRolling[J]. Journal of Process Control, 2010, 20(4),pp396-pp407.

[3] Zhou X. M., Zhang Q. D., Wu P.. The Summary of the Strip Edge Drop Control Technology[J]. ShangHai Metals.2007,29(1), pp21-pp24.
[4] ZHOU X. M., WU Y. F., MAO Y. J..The Research on the Coupling Relation between Flatness and Edge Drop for Tandem Cold Rolling Mill Advanced Materials Research. 2008,572(8),pp104-pp109.

[5] C.y. JIA, H. M. LIU. Fuzzy Shape Control Based on Elman DynamicRecursion Network Prediction Model. Journal of Iron and Steel Research International,2006,13(1),pp31-pp35.

[6] Tateno J., Kenmochi K., Yarita I.. Controlling Edge Drop by Tapered Crown Work Roll Shifting Mill and Work Roll Crossing Mill in Cold Strip Rolling. Journal of the JSTP[J],1999,(7).pp653-pp656.

[7] Lu H. T., Cao J. G., Zhang J.. Edge drop control of a taper roll during continuous cold rolling[J]. Journal of University of Science and Technology Beijing, 2006,28(8), pp774-pp777.

[8] Zhou X. M., Zhang Q. D., Wang C. S., et al. Edge Drop and Flatness Decoupling Control on UCMW Cold Mill[J].Iron and Steel,2007,42(5), pp55-pp57.

[9] Cavaliere M.A.,Goldschmit M.B.,Dvorkin E.N.. Finiteelement analysis of steel rolling processes. ComputStruct 2001,79,pp2075 - pp2089.

[10]Xiong S. W., Liu X. H., Wang G. D., et al. Three-dimensional finite elementsimulation of the vertical-horizontal rolling process in the width reductionof slab[J].Journal of Materials Processing Technology. 2000,10(1),pp146-pp151

[11] S. Chandra, U. S. Dixit. A rigid-plastic finite element analysis of temperrolling process[J]. Journal of Materials Processing Technology, 2004, 152,pp9-pp16. 